\title{
Effectiveness of HPV vaccination against the development of high-grade cervical lesions in young Japanese women
}

\author{
Yuki Shiko ${ }^{1}$, Ryo Konno ${ }^{2^{*}}$ (D, Hiroshi Konishi ${ }^{3}$, Catherine Sauvaget ${ }^{4}$, Yasuo Ohashi ${ }^{5}$ and Tadao Kakizoe ${ }^{3}$
}

\begin{abstract}
Background: Although more than 10 years have passed since HPV vaccination was implemented, first as an interim programme (Emergent vaccine promotion programme) in November 2010, followed by incorporating into the National Immunization Programme in April, 2013 and suspended in June 2013, limited studies have investigated the HPV vaccine effectiveness against high-grade cervical lesions in Japan.

Methods: We collected the matched data of the results of cervical biopsy and history of vaccination from the Japan Cancer Society database. The subjects were women aged 20 to 29 years screened for cervical cancer between April, 2015 and March, 2017, and with information on HPV vaccination status. We estimated the relative risk of developing high-grade cervical lesions in vaccinated subjects using Poisson regression as compared to unvaccinated subjects.
\end{abstract}

Results: Among the 34,281 women screened, 3770 (11.0\%) were vaccinated. The prevalence of CIN2+ was statistically significantly lower in the vaccinated women as compared to the unvaccinated women Vaccine Effectiveness $(\mathrm{VE})=76 \% ; \mathrm{RR}=0.24,95 \% \mathrm{Cl}: 0.10-0.60)$. High VE against CIN3+ was also observed (91\%; RR=0.09, 95\% Cl:0.00-0.42).

Conclusion: Women aged 20-29years who received at least one dose of HPV vaccine had a significantly lower risk of high-grade cervical lesions than those not vaccinated. In Japan, HPV vaccination should be resumed in order to reduce the incidence of cervical cancer.

Keywords: Human papillomavirus, Vaccine effectiveness, Cervical intraepithelial neoplasia, Organised screening programme, Japan

\section{Background}

The incidence rate of cervical cancer in developed countries is generally lower than that in resource-constrained settings. However, the estimated age-standardized incidence rate of cervical cancer in Japan is higher than other developed countries (14.7 per $10^{5}$ person-years in Japan; 6.5 in USA; 8.4 in UK) [1], but it is comparable to that in low- and middle-income countries such as India

\footnotetext{
* Correspondence: kryo772007@yahoo.co.jp; kryo@jichi.ac.jp

2Department of Obstetrics and Gynecology, Jichi Medical University Saitama Medical Center, Omiya-ku, Saitama 330-8530, Japan

Full list of author information is available at the end of the article
}

(14.7) or in The Philippines (14.9) [1]. This incidence rate is partly explained by the lower participation to cervical cancer screening (overall: $35.8 \%$, age $20-24: 15.1 \%$, 25-29: 36.6\%) as compared to that of developed countries (based on the Comprehensive Survey of Living Conditions, 2019 [2]). Moreover, the age-standardized mortality rate is also higher than the rates in countries of similar economical level $\left(2.7\right.$ per $10^{5}$ person-years in Japan; 1.9 in USA; 1.7 in UK) [1].

Persistent infection with human papillomavirus (HPV) can cause cervical lesions and cervical cancer [3, 4], while high efficacy of HPV vaccine has been

(c) The Author(s). 2020 Open Access This article is licensed under a Creative Commons Attribution 4.0 International License, which permits use, sharing, adaptation, distribution and reproduction in any medium or format, as long as you give appropriate credit to the original author(s) and the source, provide a link to the Creative Commons licence, and indicate if changes were made. The images or other third party material in this article are included in the article's Creative Commons licence, unless indicated otherwise in a credit line to the material. If material is not included in the article's Creative Commons licence and your intended use is not permitted by statutory regulation or exceeds the permitted use, you will need to obtain permission directly from the copyright holder. To view a copy of this licence, visit http://creativecommons.org/licenses/by/4.0/ The Creative Commons Public Domain Dedication waiver (http://creativecommons.org/publicdomain/zero/1.0/) applies to the data made available in this article, unless otherwise stated in a credit line to the data. 
demonstrated in clinical trials [5-8]. Bivalent, quadrivalent and nonavalent HPV vaccines are incorporated into National Immunization Programmes (NIPs) and they had already been introduced in 96 countries by June 2019 [9]. The nonavalent vaccine that can prevent infection by $90 \%$ of the oncogenic HPV strains has been approved in July, 2020 in Japan [6].

The bivalent vaccine, which showed $93.2 \%$ vaccine efficacy against $\mathrm{CIN} 3+$ in global clinical trial [10], was licensed in Japan in October 2009, and an interim national programme (Emergent vaccine promotion programme) started in November 2010, followed by inclusion in the NIP and given for free to girls aged 1216 years old from April 2013. However, after numerous media reports on adverse events following HPV vaccination [11], the Japanese Ministry of Health, Labor and Welfare (MHLW) suspended proactive recommendation for the vaccine in June 2013 as a precautionary measure [12]. Although a recent epidemiological study from a Japanese team reported that there was no causal association between the vaccine and reported symptoms or adverse events [13], MHLW is persisting in suspending the HPV vaccine proactive recommendation. In settings where the screening programme shows adequate performance indicators, incidence and death rates are not likely to rise even if HPV vaccination is not implemented. However, the Japanese current combined situation of suspension of HPV vaccine proactive recommendation and low screening uptake is likely to fail to reduce the cervical cancer burden [14].

Numerous clinical trials [5-8] and epidemiological studies [15-21] showed strong efficacy and effectiveness of HPV vaccine. In Japan, 10 years have passed since HPV vaccine started as an interim national programme, adolescent girls who have received the public HPV vaccine have attained the age of 20 years or older; 20 years old being the starting target age of the cervical cancer screening programme. Several studies reported the vaccine effectiveness against cervical cytological abnormalities [22, 23]. Our earlier study investigated 22,743 women who were screened for cervical cancer between April, 2015 and March, 2016. The vaccine effectiveness against histologically confirmed high-grade cervical lesions, CIN 2 or worse $(\mathrm{CIN} 2+)$ was $69 \%(\mathrm{RR}=0.31,95 \%$ CI: $0.08-0.80$ ), but effectiveness against CIN3+ could not be estimated due to the limited sample size [24]. Because of the lack of national vaccine registry and national screening registry in Japan, we cannot use the national database in order to evaluate the vaccine effectiveness in the "real world". In place of the national database, we took advantage of the JCS database, the largest database on CIN and screening of the country. This update was therefore conducted to increase the CIN3+ sample size. The purpose of this study was to investigate the effectiveness of HPV vaccine against histologically confirmed CIN2+ and CIN3+ in young women aged 20 to 29 years who underwent cervical cancer screening between April, 2015 and March, 2017.

\section{Methods}

\section{Study design and data sources}

We conducted a cross-sectional study which is an update of our earlier study, to investigate the effectiveness of HPV vaccine against histologically confirmed high-grade cervical lesions at the screening visit $(n=$ 37,505). The Japan Cancer Society (JCS) with 46 branches (equivalent of representative offices) among 47 prefectures nationwide, is the Japan's largest cancer screening organization, screening more than 11 million people every year. Some branches collect information on vaccination history, results of screening (cytology and if biopsy done, pathological results) and grade of cervical lesion. Pathological diagnosis is reported according to the WHO 2014 classification [25] and CIN classification. Women fill a self-reported questionnaire with information on vaccination history at the time of cervical cancer screening. In the present study, we collected the data from 26 branches of JCS. Among 26 branches, 7 branches did not inquire about vaccination history at screening and they were excluded. So, we finally included the data of 19 branches. The study subjects were women aged 20 to 29 years who underwent cervical cancer screening in the FY 2015 (April 2015 to March 2016) and FY2016 (April 2016 to March 2017). We defined women who received at least one dose of HPV vaccine as vaccinated. The study outcomes are histologically confirmed diagnosis of CIN2+ and CIN3 + .

\section{Statistical analyses}

The analysis was performed in two parts. In the first analysis, to evaluate the effectiveness of HPV vaccine against $\mathrm{CIN} 2+$ and $\mathrm{CIN} 3+$ for women aged 20-29 and $20-22$, we estimated the relative risk (RR) and associated $95 \%$ confidence interval $(\mathrm{CI})$ for vaccinated subjects using Poisson regression as compared to the unvaccinated subjects. We adjusted for age as fixed effect and place of screening (i.e. JCS branch) as random effect. For $\mathrm{CIN} 3+$, the number of events was small, RR and associated 95\% CIs were estimated using exact Poisson regression for aged 20-29. We adjusted for age as fixed effect in this model. Vaccine effectiveness (VE) was calculated as: (1- adjusted $R R) \times 100$.

In the MHLW guidelines, the recommended screening interval of cervical cancer is 2 years; actually, however, the intervals of screening vary depending on the local governments responsible of the 
cancer screening organization. Therefore, some women might have undergone cervical cancer screening in both FY2015 and FY2016, i.e. within less than the 2-year interval of the recommended national guidelines. We defined this fact as "overlapping". Therefore, the main analysis was performed after removing this overlapping in FY2016 (3024 women (15.6\%) screened in both FY2015 and FY2016). Statistical analyses were performed using the SAS statistical software package, Version 9.4 (SAS Institute, Cary, NC, USA).

\section{Results}

The characteristics of the subjects are shown in Table 1. Among the 37,305 women aged 20-29 years, 4083 (10.9\%) were vaccinated. The vaccination rates of 20,21 and 22 years that correspond to an interim national vaccination recipient were high at $62.7,44.6$ and $23.8 \%$, respectively, and 2.6 to $7.9 \%$ after 24 years. In the vaccinated subjects, the total number of cases of CIN2+ was only $7(0.17 \%)$ with no CIN3+. In the unvaccinated subjects, the cases of $\mathrm{CIN} 2+$ and $\mathrm{CIN} 3+$ were 188 $(0.57 \%)$ and $78(0.23 \%)$, respectively.

After removal of overlapping, we included 34,281 women in the analyses (Table 2 ). In the vaccinated subjects, the cases of CIN2+ were $5(0.13 \%)$ and no CIN $3+$. In the unvaccinated subjects, the cases of $\mathrm{CIN} 2+$ and CIN3+ were $182(0.59 \%)$ and 77 (0.25\%), respectively.

The relative risk of developing high-grade cervical lesions according to the vaccination status is shown in Table 3. Vaccine effectiveness against CIN2+ and CIN3+ was $67 \%(\mathrm{RR}=0.33,95 \% \mathrm{CI}=0.15-0.73)$ and $91 \%(\mathrm{RR}=$ $0.09,95 \% \mathrm{CI}=0.00-0.41)$, respectively. High vaccine effectiveness against $\mathrm{CIN} 2+$ was also observed for those aged $20-22$ years old $(\mathrm{VE}=77 \% ; \mathrm{RR}=0.23,95 \% \mathrm{CI}=$ $0.06-0.82)$.

In the main analysis (without overlapping), the vaccine effectiveness against $\mathrm{CIN} 2+$ and $\mathrm{CIN} 3+$ in the age-group 20-29 was $76 \%(\mathrm{RR}=0.24,95 \% \mathrm{CI}=0.10-0.60)$ and $91 \%$ $(R R=0.09,95 \% C I=0.00-0.42)$, respectively. Vaccine effectiveness against CIN2+ was also observed for those aged $20-22$ years old $(\mathrm{VE}=84 \%$; $\mathrm{RR}=0.16,95 \% \mathrm{CI}=$ $0.03-0.72$ ). The age effect was not significant in all analyses.

\section{Discussion}

In the present study, we compared the prevalence of histology confirmed $\mathrm{CIN} 2+$ and $\mathrm{CIN} 3+$ between an HPV-vaccinated subjects and unvaccinated subjects. As a result, the prevalence of CIN2+ and CIN3+ was significantly lower in the vaccinated subjects as compared to the unvaccinated subjects.

Population-based studies are also conducted in many countries [15-21]. In Scotland, the risk of CIN3+ following bivalent vaccine at age 20 years was reduced by $86 \%$ in women who were vaccinated at the age of $12-13$ years old [21]. In Sweden, the risk of CIN2+ and CIN3+ following quadrivalent vaccine was reduced by 75 and $84 \%$ in women who were vaccinated before the age of 16 years old [16]. These results were based on vaccination in women with 3 doses $[16,19]$, while our results were based on vaccination with at least one dose, because we could not obtain information on the number of doses. Several studies focused on the effectiveness of the number of doses received on CIN occurrence [26, 27]. In a case-control study from Australia, vaccine effectiveness for CIN2+ was observed in both 2- and 3-dose recipients $(\mathrm{VE}=46 \%$ in the 3 -dose recipients, $\mathrm{VE}=21 \%$ in the 2 dose recipients) [27]. In the database linkage study from

Table 1 Information on vaccination status, CIN2+ and CIN3+, among women aged 20-29 years (with overlapping)

\begin{tabular}{|c|c|c|c|c|c|c|c|}
\hline \multirow{3}{*}{$\begin{array}{l}\text { Age at } \\
\text { screening } \\
\text { (year) }\end{array}$} & \multirow{3}{*}{$\begin{array}{l}\text { Vaccine(-) } \\
\mathrm{n}\end{array}$} & \multicolumn{2}{|c|}{ Vaccine(+) } & \multicolumn{2}{|l|}{ CIN2+ } & \multicolumn{2}{|l|}{ CIN3+ } \\
\hline & & & & \multirow{2}{*}{$\begin{array}{l}\text { Vaccine(-) } \\
-\mathbf{n}\end{array}$} & \multirow{2}{*}{$\begin{array}{l}\text { Vaccine(+) } \\
\mathbf{n}\end{array}$} & \multirow{2}{*}{$\begin{array}{l}\text { Vaccine(-) } \\
\mathbf{n}\end{array}$} & \multirow{2}{*}{$\begin{array}{l}\text { Vaccine(+) } \\
\mathbf{n}\end{array}$} \\
\hline & & $\mathrm{n}$ & $\%$ & & & & \\
\hline 20 & 522 & 878 & 62.7 & 4 & 1 & 1 & 0 \\
\hline 21 & 1860 & 1496 & 44.6 & 6 & 1 & 3 & 0 \\
\hline 22 & 1569 & 489 & 23.8 & 8 & 1 & 2 & 0 \\
\hline 23 & 2517 & 217 & 7.9 & 17 & 1 & 8 & 0 \\
\hline 24 & 2985 & 214 & 6.7 & 11 & 1 & 4 & 0 \\
\hline 25 & 3035 & 149 & 4.7 & 17 & 0 & 6 & 0 \\
\hline 26 & 5367 & 189 & 3.4 & 34 & 1 & 14 & 0 \\
\hline 27 & 3849 & 128 & 3.2 & 20 & 0 & 7 & 0 \\
\hline 28 & 6820 & 184 & 2.6 & 50 & 0 & 22 & 0 \\
\hline 29 & 4698 & 139 & 2.9 & 21 & 1 & 11 & 0 \\
\hline Total & 33,222 & 4083 & 10.9 & 188 & 7 & 78 & 0 \\
\hline
\end{tabular}


Table 2 Vaccination status, CIN2+ andCIN3+, among women aged 20-29 years (without overlapping)

\begin{tabular}{|c|c|c|c|c|c|c|c|}
\hline \multirow{3}{*}{$\begin{array}{l}\text { Age at } \\
\text { screening } \\
\text { (year) }\end{array}$} & \multirow{3}{*}{$\begin{array}{l}\text { Vaccine(-) } \\
\text { n }\end{array}$} & \multicolumn{2}{|c|}{ Vaccine(+) } & \multicolumn{2}{|l|}{ CIN2+ } & \multicolumn{2}{|l|}{ CIN3+ } \\
\hline & & & & \multirow{2}{*}{$\begin{array}{l}\text { Vaccine(-) } \\
\text { n }\end{array}$} & \multirow{2}{*}{$\begin{array}{l}\text { Vaccine }(+) \\
\text { n }\end{array}$} & \multirow{2}{*}{$\begin{array}{l}\text { Vaccine(-) } \\
\text { n }\end{array}$} & \multirow{2}{*}{$\begin{array}{l}\text { Vaccine (+) } \\
\text { n }\end{array}$} \\
\hline & & $n$ & $\%$ & & & & \\
\hline 20 & 514 & 869 & 62.8 & 4 & 1 & 1 & 0 \\
\hline 21 & 1822 & 1436 & 44.1 & 5 & 1 & 3 & 0 \\
\hline 22 & 1435 & 399 & 21.8 & 8 & 0 & 2 & 0 \\
\hline 23 & 2367 & 197 & 7.7 & 17 & 1 & 8 & 0 \\
\hline 24 & 2710 & 189 & 6.5 & 11 & 1 & 4 & 0 \\
\hline 25 & 2740 & 115 & 4.0 & 17 & 0 & 6 & 0 \\
\hline 26 & 4998 & 175 & 3.4 & 33 & 1 & 14 & 0 \\
\hline 27 & 3428 & 108 & 3.1 & 20 & 0 & 7 & 0 \\
\hline 28 & 6354 & 165 & 2.5 & 48 & 0 & 22 & 0 \\
\hline 29 & 4143 & 117 & 2.8 & 19 & 0 & 10 & 0 \\
\hline Total & 30,511 & 3770 & 11.0 & 182 & 5 & 77 & 0 \\
\hline
\end{tabular}

Australia, the vaccine effectiveness against high-grade was observed in the 3-dose recipients (hazard ratio $=$ 0.86, 95\% CI: 0.78-0.94) and, women who were vaccinated before the age of 16 years old, trends of effectiveness were observed in less than 3-dose recipients [26]. A recent publication from India reported a rate of CIN1+ of $4.5 \%(5 / 132)$ in unvaccinated subjects, while there were no case $(0 / 24)$ in vaccinated women $(2$ - and 3 dose) [28]. These studies confirm that less than 3-dose

Table 3 Relative risk of developing CIN2+ and CIN3+ lesions among vaccinated women as compared to the unvaccinated women

\begin{tabular}{|c|c|c|c|c|c|c|}
\hline & \multicolumn{3}{|c|}{ CIN2+ } & \multicolumn{3}{|c|}{ CIN3+ } \\
\hline & \multicolumn{2}{|c|}{$\mathrm{RR}(95 \% \mathrm{Cl})$} & \multirow[t]{2}{*}{$P$-value } & \multicolumn{2}{|c|}{$\mathrm{RR}(95 \% \mathrm{Cl})$} & \multirow[t]{2}{*}{$P$-value } \\
\hline Aged 20-29 & & & & & & \\
\hline Unvaccinated & 1.00 & Reference & & 1.00 & Reference & \\
\hline Vaccinated & 0.33 & $(0.15,0.73)$ & 0.006 & 0.09 & $(0.00,0.41)$ & 0.002 \\
\hline Age & 1.04 & $(0.98,1.10)$ & 0.233 & 1.06 & $(0.00,1.17)$ & 0.246 \\
\hline \multicolumn{7}{|c|}{ Aged 20-29 (no overlapping) } \\
\hline Unvaccinated & 1.00 & Reference & & 1.00 & Reference & \\
\hline Vaccinated & 0.24 & $(0.10,0.60)$ & 0.003 & 0.09 & $(0.00,0.42)$ & 0.002 \\
\hline Age & 1.03 & $(0.97,1.09)$ & 0.360 & 1.06 & $(0.96,1.17)$ & 0.246 \\
\hline \multicolumn{7}{|l|}{ Aged 20-22 } \\
\hline Unvaccinated & 1.00 & Reference & & & & \\
\hline Vaccinated & 0.23 & $(0.06,0.81)$ & 0.023 & & & \\
\hline Age & 0.95 & $(0.51,1.76)$ & 0.869 & & & \\
\hline \multicolumn{7}{|c|}{ Aged 20-22(no overlapping) } \\
\hline Unvaccinated & 1.00 & Reference & & & & \\
\hline Vaccinated & 0.16 & $(0.03,0.72)$ & 0.017 & & & \\
\hline Age & 0.89 & $(0.47,1.68)$ & 0.709 & & & \\
\hline
\end{tabular}

regimens of HPV vaccine are effective against CIN, leading to the current WHO recommendation on administration of a 2-dose schedule, in subjects aged less than 13 or 14 years old depending on the vaccine (9-13 years old with the quadrivalent vaccine, 9-14 years old with the bivalent and nonavalent vaccines) [29].

Moreover, in recent reports from Denmark and Australia (with high coverage), one-dose regimen showed similar effectiveness than 3-dose regimen [30, 31]. Considering the results of these studies, it might be reasonable to support that high effectiveness of vaccine was observed in the present study.

Several limitations should be acknowledged. First, information on important confounding factors such as sexual behavior and healthcare seeking behavior were not available; consequently, the effect of these potential confounding factors could not be controlled. In addition, information on HPV types and specificity and sensitivity of CIN2+ and CIN3+ from each branch of JCS were not available. Second, HPV vaccination status was selfreported and might be affected by recall bias. Finally, the biggest limitation is that Japan has neither national vaccine registry nor national screening registry. Therefore, it is difficult to collect history of vaccination and screening results of individuals, and to link these data is even more difficult [32]. Deployment of the epidemiological surveillance at the national level is one of the most important challenges in the public health policy in Japan. Previous other studies in Japan were based on limited sample size, and on cytology results solely [22, 23]. Our early study using the data of 22,743 women from JCS showed the statistical effectiveness of the vaccine against CIN2 + only [24]. This time, we can report the statistically high effectiveness of vaccine against both $\mathrm{CIN} 2+$ and $\mathrm{CIN} 3+$, because we collected the linked data of 37, 
505 women. This is the largest study ever conducted in Japan to our knowledge.

In Japan, MHLW suspended proactive recommendation for the vaccine, as a result, uptake rate for HPV vaccine was plummeted from $70 \%$ to $0.01 \%$ [12]. Although evidence of effectiveness and safety of vaccine has been accumulated, the recommendations have not yet been resumed. Additionally, screening uptake for cervical cancer in women younger than 30 is considerably low (2019, age 20-24 15.1\%, 25-29 36.6\%) [2]. Therefore, incidence rate is increasing especially among Japanese women aged $15-39$ years old (1.69\% per years between 1975 to $1994,4.67 \%$ per year between 1994 to 2015) [33].

In Ireland, uptake rate for HPV vaccine has also declined due to concerns about vaccine safety, however the uptake rate has recovered owing to efforts such as social media and governmental campaigns [34]. Since cervical cancer is a preventable disease [35], it is important to take steps to improve the HPV vaccination uptake rate in order to discontinue the increase in incidence and mortality from cervical cancer.

The lessons learned from Japan are, unfortunately, that there is no linkage with other databases related to a screening programme such as the regional cancer registry, laboratory files, treatment files and vaccination registry. We strongly recommend an increase information technology system development to allow data collection and linkage of health data [32].

\section{Conclusions}

We showed the high vaccine effectiveness against CIN2+ and CIN3+ in Japanese young women. We hope that HPV vaccination should be recommended actively as sooner as possible, therefore incidence and mortality rates from cervical cancer will stop increasing and will eventually decline.

\section{Abbreviations \\ CIN: Cervical Intraepithelial Neoplasia; HPV: Human papillomavirus; HSIL: High-grade squamous intraepithelial lesion; JCS: The Japan Cancer Society; MHLW: Ministry of Health, Labor and Welfare; NIP: National Immunization Programme; VE: Vaccine Effectiveness}

\section{Acknowledgments}

We would like to thank all patients who participated in the study. We are grateful to the staff at the Japan Cancer Society.

\section{Declarations}

Where authors are identified as personnel of the International Agency for Research on Cancer / World Health Organization, the authors alone are responsible for the views expressed in this article and they do not necessarily represent the decisions, policy or views of the International Agency for Research on Cancer / World Health Organization.

\section{Authors' contributions}

YS analyzed the data and wrote the initial draft of the manuscript. RK conducted the study, RK, YO and CS contributed to the interpretation of data, and assisted in the preparation of the manuscript. HK and TK contributed to data collection and interpretation. All authors critically reviewed the manuscript. All authors approved the final version of the manuscript, and agreed to be accountable for all aspects of the work in ensuring that questions related to the accuracy or integrity of any part of the work are appropriately investigated and resolved.

\section{Funding}

This study is supported by the Research Programme on Emerging and Reemerging Infectious Diseases from Japan Agency for Medical Research and Development, AMED, Suga Group (JP18fk0108015). The funders had no role in study design, data collection, and analysis, decision to publish, or preparation of the manuscript.

\section{Availability of data and materials}

The datasets generated during and/or analyzed during the current study are available from the corresponding author on reasonable request.

\section{Ethics approval and consent to participate}

The appropriate research ethics committee granted an exemption of the requirement for ethics review, and deemed that informed consent was not required because the analysis used anonymized records from a pre-existing database.

\section{Consent for publication}

Not applicable.

\section{Competing interests}

RK reports his personal lecture fee from Chugai Pharmaceuticals, Japan Vaccine Co Ltd., MSD, Mochida Co Ltd., Roche Diagnostics and BD, and grant for his institute from Chugai Pharmaceuticals, outside the submitted work. $\mathrm{He}$ is the Director of the Executive Board Members of the Japanese Expert Board for the Eradication of Cervical Cancer, which has received funding from Qiagen, MSD, Chugai Pharmaceuticals and GlaxoSmithKline, outside the submitted work. Those personal fees and funding have no influence on the manuscript. YO reports personal fees from Statcom, personal fees from Sanofi, grants and personal fees from Eisai, personal fees from Chugai, personal fees from Taiho, personal fees from Shionogi, personal fees from Kowa, non-financial support from Yakult Honsha, non-financial support from Takeda, personal fees from Public Health Research Foundation, personal fees from Daiicchi-Sankyo, outside the submitted work. Those personal fees and funding have no influence on the manuscript. SY, HK, CS and TK declare no competing of interests.

\section{Author details}

${ }^{1}$ Biostatistics Section, Clinical Research Center, Chiba University Hospital, 1-8-1 Inohana, Chuo-ku, Chiba 260-8677, Japan. ²Department of Obstetrics and Gynecology, Jichi Medical University Saitama Medical Center, Omiya-ku, Saitama 330-8530, Japan. ${ }^{3}$ Japan Cancer Society, Tokyo, Japan. ${ }^{4}$ Screening Group, Early Detection and Prevention Section, International Agency for Research on Cancer (WHO), Lyon, France. ${ }^{5}$ Department of Integrated Science and Engineering for Sustainable Society, Chuo University, Tokyo, Japan.

Received: 15 August 2019 Accepted: 14 October 2020

Published online: 05 November 2020

References

1. Ferlay J, Colombet M, Soerjomataram I, Mathers C, Parkin DM, Piñeros M, et al. Estimating the global cancer incidence and mortality in 2018: GLOBOCAN sources and methods. Int J Cancer. 2019;144(8):1941-53. https://doi.org/10.1002/ijc.31937.

2. Comprehensive Survey of Living Conditions. https://www.e-stat.go.jp/statsearch/files?page $=1$ \&layout $=$ datalist\&toukei $=00450061 \&$ tstat $=000001141126$ $\&$ cycle $=7 \& t c 1 .$. ass $1=000001141142 \&$ tclass $2=000001142127 \&$ stat_infid $=000031$ 964454. Accessed 8 Oct 2020 (in Japanese).

3. Walboomers JM, Jacobs MV, Manos MM, Bosch FX, Kummer JA, Shah KV, et al. Human papillomavirus is a necessary cause of invasive cervical cancer worldwide. J Pathol. 1999;189(1):12-9. https://doi.org/10.1002/(sici)10969896(199909)189:1\%3C12::aid-path431\%3E3.0.co;2-f.

4. $\quad$ zur Hausen H. Papillomaviruses in human cancer. Appl Pathol. 1987:5(1):1924. https://doi.org/10.1046/j.1525-1381.1999.99723.x. 
5. FUTURE II Study Group. Quadrivalent vaccine against human papillomavirus to prevent high-grade cervical lesions. N Engl J Med. 2007;356(19):1915-27. https://doi.org/10.1056/nejmoa061741.

6. Huh WK, Joura EA, Giuliano AR, Iversen $O E$, de Andrade RP, Ault KA, et al. Final efficacy, immunogenicity, and safety analyses of a nine-valent human papillomavirus vaccine in women aged $16-26$ years: a randomised, doubleblind trial. Lancet (London, England). 2017;390(10108):2143-59. https://doi. org/10.1016/s0140-6736(17)31821-4.

7. Munoz N, Manalastas R Jr, Pitisuttithum P, Tresukosol D, Monsonego J, Ault $K$, et al. Safety, immunogenicity, and efficacy of quadrivalent human papillomavirus (types $6,11,16,18$ ) recombinant vaccine in women aged 24-45 years: a randomised, double-blind trial. Lancet (London, England). 2009;373(9679):1949-57. https://doi.org/10.1016/s0140-6736(09)60691-7.

8. Paavonen J, Naud P, Salmeron J, Wheeler CM, Chow SN, Apter D, et al. Efficacy of human papillomavirus (HPV)-16/18 AS04-adjuvanted vaccine against cervical infection and precancer caused by oncogenic HPV types (PATRICIA): final analysis of a double-blind, randomised study in young women. Lancet (London, England). 2009;374(9686):301-14. https://doi.org/ 10.1016/s0140-6736(09)61248-4.

9. Immunization, Vaccines and Biologicals. World Health Organization. https://www.who.int/immunization/monitoring_surveillance/en/. Accessed 8 Oct 2020

10. Lehtinen M, Paavonen J, Wheeler CM, Jaisamrarn U, Garland SM, Castellsagué X, et al. Overall efficacy of HPV-16/18 AS04-adjuvanted vaccine against grade 3 or greater cervical intraepithelial neoplasia: 4-year end-ofstudy analysis of the randomised, double-blind PATRICIA trial. Lancet Oncol. 2012;13(1):89-99. https://doi.org/10.1016/S1470-2045(11)70286-8.

11. Tsuda K, Yamamoto K, Leppold C, Tanimoto T, Kusumi E, Komatsu T, et al. Trends of media coverage on human papillomavirus vaccination in Japanese newspapers. Clin Infect Dis. 2016;63(12):1634-8. https://doi.org/10. 1093/cid/ciw647.

12. Ministry of Health Labour and Welfare and Demographic and Health Statistics. Division. Municipalities survey 2014. Tokyo. http://www.mhlw.go. jp/topics/bcg/other/5.html. Accessed 8 Oct 2020

13. Suzuki S, Hosono A. No association between HPV vaccine and reported post-vaccination symptoms in Japanese young women: results of the Nagoya study. Papillomavirus Res. 2018;5:96-103. https://doi.org/10.1016/j. pvr.2018.02.002

14. Simms KT, Steinberg J, Caruana M, Smith MA, Lew JB, Soerjomataram I, et al. Impact of scaled up human papillomavirus vaccination and cervical screening and the potential for global elimination of cervical cancer in 181 countries, 2020-99: a modelling study. Lancet Oncol. 2019;20(3):394-407. https://doi.org/10.1016/s1470-2045(18)30836-2.

15. Brotherton JM, Gertig DM, May C, Chappell G, Saville M. HPV vaccine impact in Australian women: ready for an HPV-based screening program. Med J Aust. 2016;204(5):184-e1. https://doi.org/10.5694/mja15.01038.

16. Herweijer E, Sundstrom K, Ploner A, Uhnoo I, Sparen P, Arnheim-Dahlstrom L. Quadrivalent HPV vaccine effectiveness against high-grade cervical lesions by age at vaccination: a population-based study. Int J Cancer. 2016;138(12): 2867-74. https://doi.org/10.1002/ijc.30035.

17. Markowitz LE, Liu G, Hariri S, Steinau M, Dunne EF, Unger ER. Prevalence of HPV after introduction of the vaccination program in the United States. Pediatrics. 2016;137(3):e20151968. https://doi.org/10.1542/peds.2015-1968.

18. Mesher D, Soldan K, Howell-Jones R, Panwar K, Manyenga P, Jit M, et al. Reduction in HPV 16/18 prevalence in sexually active young women following the introduction of HPV immunisation in England. Vaccine. 2013; 32(1):26-32. https://doi.org/10.1016/j.vaccine.2013.10.085.

19. Pollock KG, Kavanagh K, Potts A, Love J, Cuschieri K, Cubie H, et al. Reduction of low- and high-grade cervical abnormalities associated with high uptake of the HPV bivalent vaccine in Scotland. Br J Cancer. 2014; 111(9):1824-30. https://doi.org/10.1038/bjc.2014.479.

20. Tabrizi SN, Brotherton JM, Kaldor JM, Skinner SR, Liu B, Bateson D, et al. Assessment of herd immunity and cross-protection after a human papillomavirus vaccination programme in Australia: a repeat cross-sectional study. Lancet Infect Dis. 2014;14(10):958-66. https://doi.org/10.1016/S1473-3099(14)70841-2.

21. Palmer T, Wallace L, Pollock KG, Cuschieri K, Robertson C, Kavanagh K, et al. Prevalence of cervical disease at age 20 after immunisation with bivalent HPV vaccine at age 12-13 in Scotland: retrospective population study. BMJ. 2019;365:11161. https://doi.org/10.1136/bmj.l1161.
22. Ozawa N, Ito K, Tase T, Metoki H, Yaegashi N. Beneficial effects of human papillomavirus vaccine for prevention of cervical abnormalities in Miyagi. Japan Tohoku J Exp Med. 2016;240(2):147-51. https://doi.org/10.1620/tjem.240.147.

23. Tanaka H, Shirasawa H, Shimizu D, Sato N, Ooyama N, Takahashi O, et al. Preventive effect of human papillomavirus vaccination on the development of uterine cervical lesions in young Japanese women. J Obstet Gynaecol Res. 2017;43(10):1597-601. https://doi.org/10.1111/jog.13419.

24. Konno R, Konishi H, Sauvaget C, Ohashi Y, Kakizoe T. Effectiveness of HPV vaccination against high-grade cervical lesions in Japan. Vaccine. 2018; 36(52):7913-5. https://doi.org/10.1016/j.vaccine.2018.05.048.

25. Kurman RJ, Carcangiu ML, Herrington CS, Young RH. WHO Classification of Tumours of Female Reproductive Organs, 4th ed.: IARC; 2014.

26. Brotherton JML, Malloy M, Budd AC, Saville M, Drennan KT, Gertig DM. Effectiveness of less than three doses of quadrivalent human papillomavirus vaccine against cervical intraepithelial neoplasia when administered using a standard dose spacing schedule: observational cohort of young women in Australia. Papillomavirus Res. 2015;1:59-73. https://doi.org/10.1016/j.pvr.2015.05.005.

27. Crowe E, Pandeya N, Brotherton JM, Dobson AJ, Kisely S, Lambert SB, et al. Effectiveness of quadrivalent human papillomavirus vaccine for the prevention of cervical abnormalities: case-control study nested within a population based screening programme in Australia. BMJ. 2014;348:g1458. https://doi.org/10.1136/bmj.g1458.

28. Basu P, Muwonge R, Bhatla N, Nene BM, Joshi S, Esmy PO, et al. Two-dose recommendation for human papillomavirus vaccine can be extended up to 18 years - updated evidence from Indian follow-up cohort study. Papillomavirus Res. 2019;7:75-81. https://doi.org/10.1016/j.pvr.2019.01.004.

29. WHO Position Paper on Vaccines against Human Papillomavirus (HPV) https://www.who.int/immunization/policy/position_papers/hpv/en/. Accessed 8 Oct 2020.

30. Brotherton JM, Budd A, Rompotis C, Bartlett N, Malloy MJ, Andersen RL, et al. Is one dose of human papillomavirus vaccine as effective as three?: a national cohort analysis. Papillomavirus Res. 2019;8:100177. https://doi.org/ 10.1016/j.pvr.2019.100177.

31. Verdoodt F, Dehlendorff C, Kjaer SK. Dose-related effectiveness of quadrivalent human papillomavirus vaccine against cervical intraepithelial neoplasia: a Danish nationwide cohort study. Clin Infect Dis. 2019. https:// doi.org/10.1093/cid/ciz239.

32. Sauvaget $C$, Nishino $Y$, Konno R, Tase T, Morimoto T, Hisamichi S. Challenges in breast and cervical cancer control in Japan. Lancet Oncol. 2016;17(7):e305-e12. https://doi.org/10.1016/s1470-2045(16)30121-8.

33. Cancer Registry and Statistics. Cancer Information Service, National Cancer Center, Japan. http://gdb.ganjoho.jp/graph_db/gdb1. Accessed 8 Oct 2020 (in Japanese).

34. Corcoran B, Clarke A, Barrett T. Rapid response to HPV vaccination crisis in Ireland. Lancet (London, England). 2018;391(10135):2103. https://doi.org/10. 1016/s0140-6736(18)30854-7.

35. WHO Director-General calls for all countries to take action to help end the suffering caused by cervical cancer. https://www.who.int/reproductivehealth/ call-to-action-elimination-cervical-cancer/en/. Accessed 8 Oct 2020.

\section{Publisher's Note}

Springer Nature remains neutral with regard to jurisdictional claims in published maps and institutional affiliations.

Ready to submit your research? Choose BMC and benefit from:

- fast, convenient online submission

- thorough peer review by experienced researchers in your field

- rapid publication on acceptance

- support for research data, including large and complex data types

- gold Open Access which fosters wider collaboration and increased citations

- maximum visibility for your research: over $100 \mathrm{M}$ website views per year

At BMC, research is always in progress.

Learn more biomedcentral.com/submission 